\title{
Covid-19: análisis métrico de vídeos y canales de comunicación en YouTube
}

\section{Covid-19: metric analysis of videos and communication channels on YouTube}

\author{
Enrique Orduña-Malea; Cristina I. Font-Julián; José-Antonio Ontalba-Ruipérez
}

Cómo citar este artículo:

Orduña-Malea, Enrique; Font-Julián, Cristina I.; Ontalba-Ruipérez, José-Antonio (2020). “Covid-19: análisis métrico de vídeos y canales de comunicación en YouTube". El profesional de la información, v. 29, n. 4, e290401. https://doi.org/10.3145/epi.2020.jul.01

Artículo recibido el 11-05-2020 Aceptación definitiva: 19-05-2020

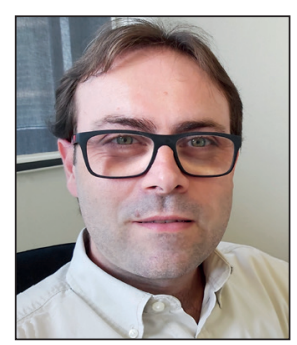

Enrique Orduña-Malea $\bowtie$
https://orcid.org/0000-0002-1989-8477

Universitat Politècnica de València

Camí de Vera, s/n. 46020 Valencia, España enorma@upv.es

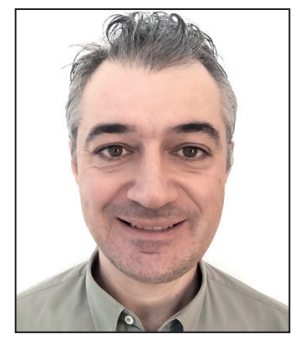

José-Antonio Ontalba-Ruipérez

https://orcid.org/0000-0002-2071-6108

Universitat Politècnica de València

Camí de Vera, s/n. 46020 Valencia, España

joonrui@upv.es

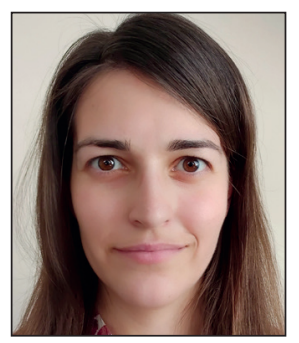

Cristina I. Font-Julián https://orcid.org/0000-0003-2351-4816

Universitat Politècnica de València Camí de Vera, s/n. 46020 Valencia, España crifonju@upv.es

\section{Resumen}

El objetivo de este trabajo es determinar el volumen de vídeos sobre Covid-19 publicados y difundidos a través de YouTube y relacionados directa o indirectamente con el territorio nacional español, caracterizar su impacto (en términos de visualizaciones, likes y comentarios recibidos), y finalmente categorizar los canales a través de los cuales se han difundido. Para ello se han analizado 39.531 vídeos publicados entre el 1 enero y el 30 de abril de 2020. Los resultados muestran que el número de vídeos sobre Covid-19 aumentaron a partir del establecimiento del estado de alarma en España y, poco a poco, han ido disminuyendo en el tiempo, con ciertos repuntes vinculados a decisiones políticas. Los vídeos logran en promedio un gran número de visualizaciones, likes/dislikes y comentarios, y han sido publicados principalmente por medios de comunicación. Los vídeos relacionados con blogs y entretenimiento son muy numerosos pero con menor impacto. Los vídeos pertenecientes a las categorías de Educación y Ciencia y Tecnología son menos numerosos pero con un alto impacto, especialmente en visualizaciones. De forma complementaria, se concluye que los criterios de ordenación de YouTube no son lo suficientemente precisos como para ser utilizados en estudios informétricos sin una alta carga de trabajo en limpieza de datos. Así mismo, la existencia de canales que aplican estrategias engañosas de posicionamiento dificulta la realización de este tipo de estudios.

\section{Palabras clave}

Coronavirus; Covid-19; Pandemias; Información de salud; Video; YouTube; Redes sociales; Informetría; España.

\section{Abstract}

The objective of this work is to determine the volume of videos on Covid-19 published and disseminated through YouTube, and directly or indirectly related to the Spanish national territory, to characterize the impact of those videos (in terms of views, likes and comments received), and finally to categorize the channels through which the videos have been broadcast. For this, 39,531 videos published between January 1 and April 30, 2020 have been analysed. The results show 
that the number of videos on Covid-19 grew since the establishment of the state of alarm in Spain, and they have been slightly decreasing over time, including certain upswings linked to political decisions. The videos achieve on average high volumes of views, likes/dislikes and comments, and have been published mainly by the media. The videos related both to Blogs and Entertainment are very numerous but with less impact. The videos belonging to the categories of Education and Science and Technology are less numerous, but had a high impact, especially in view counts. In addition, it is concluded that YouTube search filters are not accurate enough to be used in informetric studies without a high data cleansing workload. Likewise, the existence of channels applying defective positioning techniques makes it difficult to carry out this type of study.

\section{Keywords}

Coronavirus; Covid-19; Pandemics; Health information; Video; YouTube; Informetrics; Social media; Spain.

\section{Introducción}

Covid-19 (inicialmente denominado 2019-nCoV, novel coronavirus) es una enfermedad infecciosa de origen presumiblemente zoonótico ocasionada por el virus 'coronavirus 2 del síndrome respiratorio agudo grave' (SARS-CoV-2), perteneciente a la especie 'coronavirus SARS' (Severe Acute Respiratory Syndrome), virus identificado por vez primera en 2003 (WHO, 2003). El primer caso detectado de Covid-19 (que haya sido notificado oficialmente) se produjo en la ciudad de Wuhan (China) el 1 de diciembre de 2019 (Huang et al., 2020). A partir de ahí, el Comité de Emergencias del Reglamento Sanitario Internacional de la Organización Mundial de la Salud (World Health Organization, WHO) declaró el brote de Covid-19 como una emergencia de salud pública de interés internacional el 30 de enero de 2020 (WHO, 2020a) y como una pandemia el 11 de marzo de 2020 (WHO, 2020b). A fecha de 11 de mayo de 2020 (17.07 GMT) se notificaron oficialmente 3,23 millones de ciudadanos infectados por Covid-19 en 214 países y 285.260 fallecimientos (Coronavirus Resource Center, 2020).

El sábado 14 de marzo de 2020 se decretó el estado de alarma en el territorio español (España, 2020) como consecuencia de la propagación del virus (268.143 contagiados y 26.744 fallecidos a fecha de 11 de mayo de 2020), y comenzó una etapa de "confinamiento" que coincidió con medidas similares en otros países.

Durante este período se detectó un aumento sin precedentes del tráfico de internet (Nokia, 2020). Telefónica notificó un incremento del 35\% en el tráfico de internet en España en su red fija (RedIP) entre el 10 de marzo y el 12 de abril, equivalente al que se produce en todo un año (Telefónica, 2020). El tiempo medio semanal en internet aumentó igualmente, de forma especial en personas jóvenes entre 16 y 24 años (Hidalgo-Pérez, 2020).

Más allá de la intensidad de uso, la paralización y/o redefinición de las actividades laborales conllevó un cambio en las tendencias de consumo de contenidos de los usuarios, detectándose aumentos significativos en ciertas categorías (noticias generales, sitios de mensajería instantánea, tiendas de comestibles, educación y entretenimiento), aunque con diferencias notables entre países (Gevers, 2020). De forma especialmente acusada, se detectó un aumento en el consumo de vídeo en streaming, principalmente Netflix y YouTube (Nokia, 2020).

Con el fin de controlar la capacidad de los operadores de red ante este incremento en la demanda, Berec (Body of European Regulators for Electronic Communications), en coordinación con la Comisión Europea, acordó establecer una monitorización regular de la situación del tráfico en internet en cada estado miembro de la Unión Europea (Berec, 2020). https://berec.europa.eu/eng/document_register/subject_matter/berec/reports

Siguiendo las indicaciones del comisario europeo de mercado interior Thierry Breton, se solicitó a los principales proveedores de contenidos que pusieran en marcha acciones para reducir la carga en las infraestructuras de internet durante la crisis de la pandemia. Como consecuencia, Amazon Prime, Facebook, Netflix o YouTube se comprometieron a reducir temporalmente la calidad de los vídeos.

YouTube destaca entre estos servicios por ser una plataforma a la que los usuarios acceden no sólo para buscar entretenimiento sino también para buscar noticias confiables y material didáctico, mantener relaciones familiares y fortalecer relaciones profesionales. Entre febrero y marzo de 2020 el sitio web de YouTube presentó un crecimiento de 3.985 millones de visitantes, según datos de Similarweb.

https://www.similarweb.com/website/YouTube.com\#overview

Un estudio realizado por la empresa 2 btube, grupo de medios que gestiona más de 500 canales de YouTube en España con una audiencia de más de 8 millones de usuarios únicos (aproximadamente el 25\% de los usuarios de YouTube de España), identificó igualmente un aumento de las visitas a los canales que gestiona del $37 \%$ a nivel global, y del $55 \%$ a nivel nacional (de 58 millones en la primera quincena de marzo a 90 millones de visitas en la segunda quincena de ese mes). http://2btube.com

El incremento del uso de YouTube no se limitó al visionado de material sino también a la difusión de vídeos relacionados con la pandemia. De este modo, se pueden identificar noticias producidas por medios de comunicación respecto a los últimos acontecimientos (sociales, económicos y políticos) relacionados con Covid-19, vídeos divulgativos para prevenir 
el contagio procedentes de servicios de salud, noticias falsas, vídeos académicos relacionados con aspectos más técnicos o científicos, vídeos de usuarios individuales que reflejan vivencias personales o profesionales durante el confinamiento o servicios de información en streaming con estadísticas oficiales (como el Coronavirus Life Map). De hecho, YouTube generó paneles de información sobre salud dentro de los resultados de sus búsquedas para proporcionar a los usuarios enlaces a fuentes confiables, habilitó botones de donación en determinados canales de vídeos y comenzó a regular las condiciones de monetización de vídeos mencionando Covid-19.

https://www.YouTube.com/watch?v=x6UiR9Rs6dA

https://support.google.com/YouTube/answer/9777243

En la figura 1 se puede apreciar el interés en búsquedas sobre coronavirus en los principales países afectados a través de Google Trends. Aunque los resultados de esta web deben considerarse con cierta cautela (Orduña-Malea, 2019), la evolución del interés muestra un incremento de búsquedas a principios de marzo de 2020 y un paulatino decrecimiento conforme la etapa de confinamiento se alarga, patrón que se repite en todos los países analizados.

El análisis de los vídeos difundidos a través de YouTube relacionados con Covid-19 durante la etapa de confinamiento puede ser de gran ayuda

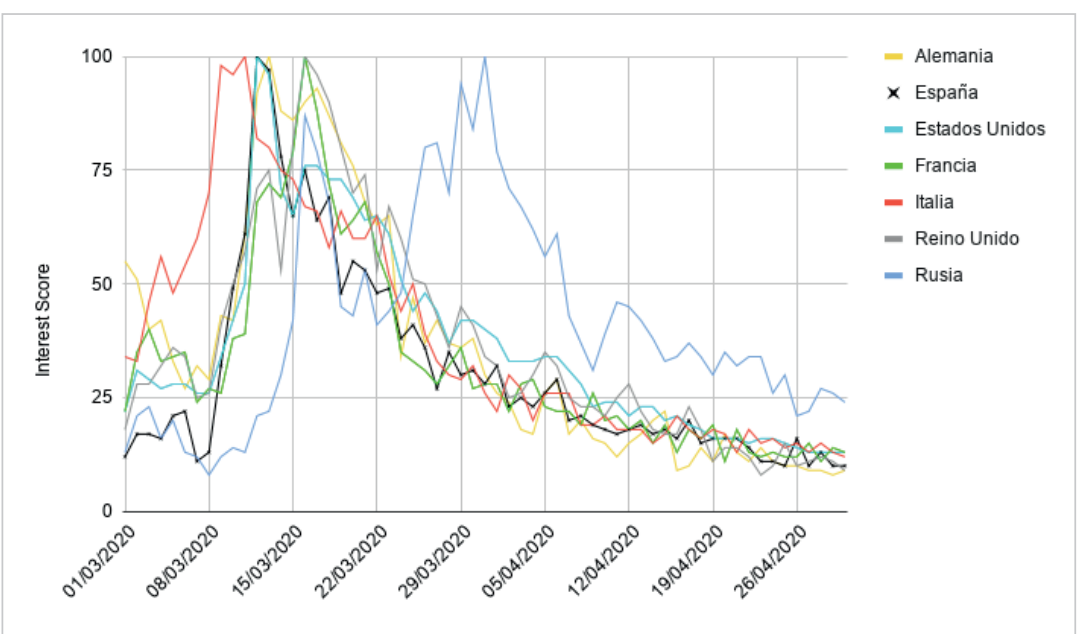

Figura 1. Tendencias de búsqueda sobre coronavirus en Alemania, España, Estados Unidos, Francia, Italia, Reino Unido y Rusia, a través de Google Trends para conocer qué contenidos fueron generados, qué usuarios los generaron y qué tipo de impacto tuvo ese material. Si este análisis se restringe adicionalmente a un entorno territorial definido, como puede ser España, los resultados pueden arrojar información de un valor social inestimable para ayudar a identificar y describir el comportamiento de la sociedad española ante una situación excepcional como la generada por la pandemia del Covid-19.

Este potencial objetivo abre una línea de investigación de gran envergadura y complejidad que requerirá de análisis de diferentes campos del conocimiento. De forma exploratoria, los objetivos principales de este trabajo se centran en determinar la cantidad y evolución del número de vídeos sobre Covid-19 relacionados con España en YouTube, calcular el impacto de estos vídeos y, finalmente, en identificar desde qué tipo de canales se difunden.

De forma complementaria, se plantea determinar la precisión de YouTube como fuente para la realización de estudios informétricos en los que se precisa la obtención de grandes cantidades de vídeos relacionados con un tema específico en un territorio definido.

\section{YouTube como herramienta de análisis}

YouTube es una plataforma de red social para la compartición de vídeos creada el 14 de febrero de 2005 por tres antiguos trabajadores de PayPal. Fue adquirida por Google (ahora Alphabet) en noviembre de 2006 por 1.650 millones de dólares estadounidenses.

La plataforma permite, por una parte, la búsqueda y visionado de vídeos así como ciertas funcionalidades de interacción (seguir a usuarios, marcar like/dislike a vídeos, incluir comentarios, etc.) y, por otra parte, la creación de perfiles de usuario (canales), a través de los cuales se pueden almacenar y difundir vídeos elaborados por los propios usuarios.

YouTube mantiene un modelo de negocio a dos niveles. En primer lugar, dispone de un servicio gratuito (búsqueda y visualización de vídeos, creación de playlists, etc.) que se mantiene económicamente a través de publicidad (lo que supone para los usuarios la posibilidad de monetizar la visualización de sus vídeos). En segundo lugar, ofrece un servicio premium de pago sin publicidad.

YouTube alcanza aproximadamente los 2.000 millones de usuarios en todo el mundo a inicios de 2020 (usuarios registrados por mes), número solamente superado por Facebook. El tamaño de YouTube no se conoce con exac-

Los vídeos de Educación y Ciencia y Tecnología logran un alto impacto en visualizaciones y likes titud, aunque las estadísticas indican que se depositan alrededor de 500 horas de vídeo cada minuto (Statista, 2020) y diariamente se visualizan en promedio 1.000 millones de horas de vídeo. Con cerca de 4.000 millones de visitantes mensuales, YouTube.com es el segundo sitio web del mundo en tráfico web, solamente superado por Google (ambos pertenecientes a la misma empresa).

https://www.youtube.com/about/press 


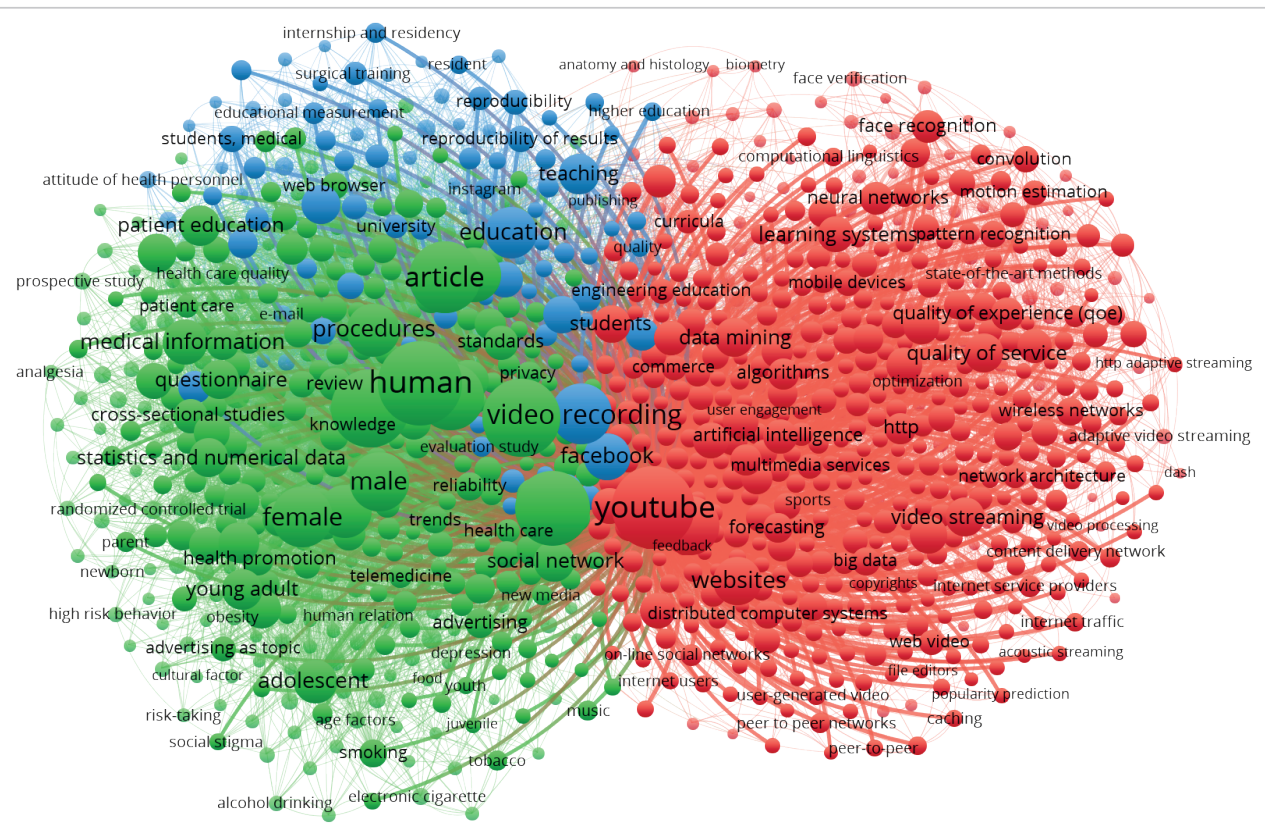

Figura 2. Mapa de co-ocurrencia de palabras clave en publicaciones indexadas por Scopus que contienen el término YouTube. Visualización realizada con Vosviewer

http://www.vosviewer.com

Cluster rojo: agrupación de términos relacionados con internet, multimedia y tecnología web. Cluster azul: agrupación de términos relacionados con universidad, educación y enseñanza. Cluster verde: agrupación de términos relacionados con estudios sociales, incluyendo salud.

Con esas cifras no es de extrañar que YouTube aportara el 9,4\% de las ganancias por publicidad de Google en 2019. Los ingresos brutos de YouTube en el primer trimestre de 2020 ascendieron a 4.038 millones de dólares estadounidenses.

El empleo de YouTube en la bibliografía científica (tanto como objeto de análisis como fuente de datos) es frecuente. Hasta la fecha se identifican 9.343 publicaciones indexadas en Scopus que contengan el término YouTube (o mencionen YouTube.com), de las cuales el 11,9\% pertenece a publicaciones relacionadas con la medicina (fig. 2).

De las 33.831 palabras clave contenidas en ese corpus bibliográfico, se observa la alta presencia de términos relacionados con la Salud, por ejemplo: health education (98 ocurrencias), consumer health information (77), health promotion (66), public health (61), health care personnel (59), attitude to health (46), health communication (41) o health (37). Estos datos reflejan el uso de YouTube por parte de la comunidad científica, que puede ser utilizado para conocer las actitudes y comportamiento tanto de los consumidores como de los productores de información en salud (Burton et al., 2012).

Una de las principales líneas de investigación se centra en el uso de YouTube como fuente de información sanitaria por parte de los usuarios, así como en la evaluación y calidad de sus contenidos (Hayanga; Kaiser, 2008; Sampson et al., 2013; Madathil et al., 2015; Oller-Arlandis; Oller-Arlandis, 2017; Drozd et al., 2018) y la propagación de información engañosa relacionada con la salud (Syed-Abdul et al., 2013).

Por otro lado, YouTube ha sido igualmente utilizado para conocer la cobertura, difusión e impacto de vídeos relacionados con enfermedades contagiosas como el Ébola (Basch et al., 2015; Pathak et al., 2015), la Gripe A (Pandey et al., 2010; Walton; Seitz; Ragsdale, 2012) o el virus Zika (Basch et al., 2017).

La bibliografía científica centrada en Covid-19 y YouTube está emergiendo, aunque es todavía escasa. Khatri et al. (en prensa) analizan la cobertura en YouTube de vídeos relacionados con el coronavirus en inglés y chino, detectando unas altas tasas de visionados y unos significativos porcentajes de vídeos con información engañosa, especialmente en idioma chino. Cinelli et al. (2020) analizan en torno a 8 millones de posts y comentarios sobre Covid-19 en varias plataformas (Twitter, Instagram, YouTube, Reddit y Gab) publicados en un período de 45 días, a través de consultas genéricas en inglés. En el caso concreto de YouTube, los autores detectan un alto volumen de interactividad (posts y comentarios) y de fuentes no confiables. Finalmente, Basch et al. (2020) analizan el contenido de los 100 vídeos con mayor número de visualizaciones relacionados con Covid-19 y llegan a la conclusión de que la mayoría de los vídeos mencionan 'muerte', 'ansiedad' o 'miedo', así como términos relacionados con restricciones de viajes y cuarentena. Sin embargo, los vídeos mencionando síntomas o métodos de prevención son minoritarios.

No se identifican en la bibliografía estudios que cubran un territorio específico o zona geográfica delimitada, un aspecto de gran importancia a la hora de analizar la difusión y popularidad de vídeos relacionados con la pandemia debido a las distintas normas de confinamiento aplicadas en cada país y al diferente grado de penetración de la enfermedad en cada territorio. En el caso de España, siendo actualmente una de las naciones con una mayor tasa de contagiados y fallecidos por unidad de población (a fecha de mayo de 2020), el análisis resulta de especial importancia y necesidad. 


\section{Metodología}

La recopilación de vídeos sobre Covid-19 se realizó a través de YouTube Data API v3. Este servicio es gratuito, pero presenta limitaciones de uso. La documentación oficial indica un límite de 10.000 unidades diarias (cada operación realizada en la API consume un número determinado de unidades), aunque en la práctica el número de resultados se reduce a menos de 700 por consulta, consumiendo además una mayor cantidad de unidades de cuota de uso al sobrepasar los 500 resultados.

https://developers.google.com/youtube/v3/getting-started

Por este motivo se decidió aplicar un sistema de consultas basado en query splitting de forma que se pudiera obtener un mayor número de resultados. Para ello se diseñaron consultas con dos componentes:

- Componente 1 (enfermedad): 'Covid-19', 'SARS-CoV-2' y 'coronavirus'.

- Componente 2 (localización): nombre del país, de cada comunidad autónoma (NUTS 2) y de cada provincia (NUTS 3). Se incluyeron capitales de provincia cuyo nombre no coincide con el nombre de la provincia. Finalmente, se incluyeron todas las variantes en idiomas oficiales locales.

YouTube permite la utilización de llamadas a la API utilizando distintos criterios de ordenación de resultados (fecha de publicación, rating obtenido por los vídeos, relevancia, título, número de vídeos, número de visionados). Ante una misma consulta, los vídeos recuperados según cada criterio de ordenación varían sensiblemente. Dada la restricción del número máximo de resultados obtenidos para cada consulta (en torno a 700), se decidió repetir cada consulta utilizando todas las opciones de ordenación de resultados disponibles con el fin de obtener una mayor cantidad de vídeos únicos sin duplicados.

Este diseño produjo 1.602 consultas ( 3 variantes de nombre de enfermedad x 89 términos geográficos $\times 6$ factores de ordenación), que se ejecutaron directamente a través de la aplicación Webometric analyst (Thelwall, 2012), desarrollada por el Statistical Cybermetrics Research Group (University of Wolverhampton) durante el 29 y 30 de abril de 2020. Se recopilaron 200.647 vídeos que, tras eliminar duplicados, quedaron reducidos a 73.268 vídeos únicos procedentes de 31.431 canales.

http://lexiurl.wlv.ac.uk

En la figura 3 se puede observar la cantidad de resultados únicos (nú-

mero de vídeos sin duplicados) obtenidos para todas las consultas delimitadas geográficamente a nivel de provincia, donde se aprecia una gran cantidad de resultados devueltos ante consultas incluyendo los términos de Madrid, Castellón y Baleares. Estos datos no deben tomarse en valor absoluto (corresponden al número de vídeos diferentes ante cada búsqueda geográfica) aunque permiten conocer de forma aproximada la respuesta de YouTube a consultas específicas sobre el virus cuando el usuario incorpora el nombre de la provincia en su búsqueda.

Para cada uno de los vídeos obtenidos se realizó una segunda consulta a la YouTube Data API con el fin de extraer métricas a nivel de vídeo (fecha de publicación, duración, y número de visionados, likes/dislikes y comentarios recibidos) así como aspectos descriptivos (canal, título y descripción). Las métricas se obtuvieron a fecha de 6 de mayo de 2020.

A partir de los datos obtenidos se observó una cantidad de ruido documental significativa (vídeos no relacionados con Covid-19). Por este motivo, se aplicó un filtrado a partir del análisis textual de los campos título y descripción de cada vídeo. De los 73.268 vídeos analizados se obtuvieron 39.702 relacionados con Covid-19. De éstos, 39.531 habían sido publicados entre el 1 enero y el 30 de abril de 2020. Este corpus de vídeos constituye la base del análisis estadístico de este trabajo.

En la tabla 1 se ofrece la cantidad de resultados obtenidos para cada consulta por variante de enfermedad (coronavirus, Covid-19 y sars-cov-2). En números totales, las consultas incluyendo 'coronavirus' fueron las más voluminosas, aunque el mayor número de vídeos únicos se obtuvo en las consultas incluyendo el término 'Covid-19'.
Tabla 1. Solapamiento entre consultas sobre Covid-19 en YouTube

\begin{tabular}{|l|c|c|c|c|}
\hline Items recogidos & Coronavirus & Covid-19 & SARS-COV-2 & Total \\
\hline Vídeos totales & 99.709 & 88.255 & 12.683 & 200.647 \\
\hline Vídeos únicos & 39.839 & 40.288 & 7.928 & 73.268 \\
\hline Canales únicos & 16.912 & 18.504 & 4.879 & 31.431 \\
\hline
\end{tabular}




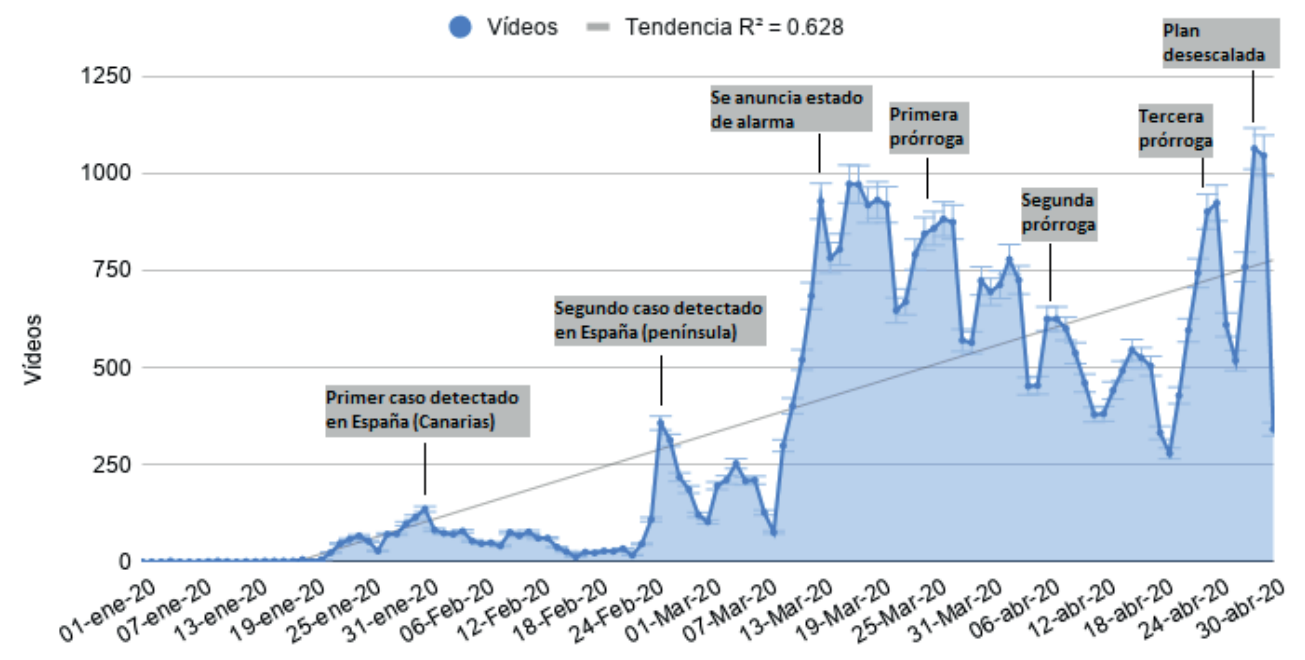

Figura 4. Evolución del número de vídeos publicados sobre Covid-19 en YouTube en los que se menciona España (enero-abril 2020)

\section{Resultados}

En la figura 4 se puede apreciar la evolución diaria de publicación de los 39.531 vídeos, observándose picos de publicación vinculados a situaciones sociales (casos detectados) y políticas (aprobación del estado de alarma y sus sucesivas prórrogas). Igualmente, se aprecian caídas en la publicación durante los fines de semana (efecto diente de sierra, apreciable a partir de la entrada en vigor del estado de alarma el 14 de marzo). Tras una paulatina caída en la cantidad de vídeos (que concuerda con los datos proporcionados en la figura 1), se observa un repunte a partir del anuncio de la tercera prórroga ( 22 abril) y el comienzo del plan de desescalada, anunciado el 28 de abril.

La publicación de vídeos sobre 'Covid-19 en España' se incrementó a partir de la entrada en vigor del estado de alarma en marzo de 2020

Entre los vídeos obtenidos se aprecia una gran variedad (vídeos de noticias procedentes de medios de comunicación, vídeos didácticos o de divulgación, vídeos con canciones relacionadas con la pandemia, acciones solidarias de personas famosas, testimonios personales, así como vídeos con falsedades y seudocientíficos).

A pesar de la inclusión de descriptores geográficos en las consultas, YouTube ha proporcionado vídeos en multitud de idiomas y localizaciones. El 71,7\% de los vídeos presentan un título y/o descripción en castellano, mientras que este porcentaje se reduce al $16,2 \%$ en el caso del inglés. Igualmente, el catalán presenta un porcentaje de vídeos destacado $(6,6 \%)$, seguido del portugués $(2,78 \%)$, italiano $(1,9 \%)$, gallego $(1,36 \%)$, francés $(1,25 \%)$ y alemán $(1,1 \%)$.

Si se consideran todos los vídeos obtenidos con independencia del idioma, el vídeo con mayor número de likes recibidos (1.004.807 hasta la fecha) ha sido una publicación de entretenimiento para jóvenes (Canciones del coronavirus) del influencer español El Rubius. El vídeo con más comentarios recibidos (85.958) ha sido una noticia publicada por CNN (Bill Gates makes a prediction about when coronavirus cases will peak). El vídeo con más dislikes (62.517) ha correspondido a un montaje musical (25 celebrities sing 'Imagine' in isolation, creating a moving montage), publicado por CBS News.

En el caso de vídeos en castellano, el vídeo con mayor número de visualizaciones ha sido Resistiré 2020, la canción homenaje a la pandemia producida por Warner Music Spain e interpretada por más de 30 artistas confinados en sus hogares (28.699.731 visualizaciones). Por otra parte, el ya citado vídeo de El Rubius (Canciones del Coronavirus), aparte de ser el que más likes ha recibido en términos absolutos, también es el que más dislikes (17.085) y comentarios (60.975) ha recibido entre los vídeos en español.

Por otro lado, los canales de noticias en streaming (por ejemplo, TV9 Marathi o ABC News), así como vídeos en streaming ofreciendo datos estadísticos (por ejemplo, Roylab Stats), han logrado una gran cantidad de visualizaciones, aunque los datos de audiencia exacta no se pueden calcular con precisión a través de la API.

En la tabla 2 se muestran los 10 vídeos con un mayor número de visualizaciones (excluyendo las reproducciones en streaming, por su naturaleza especial) así como el número de likes, dislikes y comentarios que esos vídeos han recibido. Entre estos vídeos destacan tres documentales breves, publicados por Kurzgesagt (animación de orientación divulgativa e informativa), Vox (documental de orientación conspirativa sobre el papel del gobierno

El conocido influencer El Rubius es el autor del vídeo en español sobre coronavirus con mayor número de likes hasta la fecha 
chino en el origen de la pandemia) y Dr. Angelo Estrada (explicación divulgativa acerca de la naturaleza de la enfermedad por parte de un especialista).

Tabla 2. Vídeos con mayor número de visualizaciones (views) en YouTube sobre coronavirus para consultas delimitadas mediante términos geográficos a nivel nacional

\begin{tabular}{|c|c|c|c|c|c|}
\hline Título & Canal & Views & Likes & Dislikes & Comments \\
\hline $\begin{array}{l}\text { Coronavirus की Inside Story! | Vardaat with Shams Tahir Khan } \\
\text { https://youtu.be/JJsqVMRSW-8 }\end{array}$ & Aaj Tak & 55.090 .504 & 363.659 & 52.531 & 12.584 \\
\hline $\begin{array}{l}\text { Ghen Cô Vy| NIOEH x K.HU'NG } \\
\text { x MIN x ERIK | WASHING HAND SONG | CORONA SONG } \\
\text { https://youtu.be/BtulL3oArQw }\end{array}$ & MIN OFFICIAL & 44.089 .795 & 514.749 & 21.782 & 23.406 \\
\hline $\begin{array}{l}\text { Andrea Bocelli: Music For Hope - Live From Duomo di Milano } \\
\text { https://youtu.be/huTUOek4LgU }\end{array}$ & Andrea Bocelli & 39.507 .008 & 929.066 & 21.473 & 25.533 \\
\hline $\begin{array}{l}\text { Resistiré 2020 - Video Oficial } \\
\text { https://youtu.be/hl3B4Q/8RtQ }\end{array}$ & Warner Music Spain & 28.699 .731 & 458.723 & 14.935 & 23.858 \\
\hline $\begin{array}{l}\text { The Coronavirus Explained \& What You Should Do } \\
\text { https://youtu.be/BtN-goygVOY }\end{array}$ & Kurzgesagt & 23.918 .816 & 865.875 & 10.604 & 48.204 \\
\hline $\begin{array}{l}\text { How wildlife trade is linked to coronavirus } \\
\text { https://youtu.be/TPpoJGYIW54 }\end{array}$ & Vox & 22.223 .085 & 393.032 & 21.950 & 59.749 \\
\hline $\begin{array}{l}\text { Do I have Coronavirus? Coronavirus Suspect Ke Saath Kya Karte } \\
\text { Hain? Mamta Sachdeva } \\
\text { https://youtu.be/86tAXsYpxxc }\end{array}$ & TravelwithMamta & 17.874 .819 & No disponible & No disponible & 36.756 \\
\hline $\begin{array}{l}\text { Que es el coronavirus (Origen) } \\
\text { https://youtu.be/b07gvHql47Q }\end{array}$ & Dr. Angelo Estrada & 16.883 .046 & 177.936 & 13.186 & 7.570 \\
\hline $\begin{array}{l}\text { Chinese Police Force Family Into Coronavirus Quarantine } \\
\text { https://youtu.be/rKekOY30Ctw }\end{array}$ & VOA News & 16.715 .246 & 60.681 & 11.014 & 9.294 \\
\hline $\begin{array}{l}\text { China में कैसे फैला Dangerous Coronavirus, जसिका खतरा India, } \\
\text { America \& Saudi Arab तक पहुंच गया है } \\
\text { https://youtu.be/8pCvN81jHos }\end{array}$ & Navbharat Times & 14.629 .940 & 247.768 & 12.583 & 14.954 \\
\hline
\end{tabular}

De forma complementaria, la tabla 3 incluye los 10 vídeos en castellano publicados por canales españoles (u orientados al mercado español) con mayor número de visualizaciones.

Tabla 3. Vídeos en español con mayor número de visualizaciones (views) en YouTube sobre coronavirus para consultas delimitadas mediante términos geográficos a nivel nacional

\begin{tabular}{|c|c|c|c|c|c|}
\hline Título & Canal & Views & Likes & Dislikes & Comments \\
\hline $\begin{array}{l}\text { Resistiré } 2020 \text { - Video Oficial } \\
\text { https://youtu.be/hI3B4QI8RtQ }\end{array}$ & Warner Music Spain & 28.699 .731 & 458.723 & 14.935 & 23.858 \\
\hline $\begin{array}{l}\text { Que es el coronavirus (Origen) } \\
\text { https://youtu.be/b07gvHql47Q }\end{array}$ & Dr. Angelo Estrada & 16.883 .046 & 177.936 & 13.186 & 7.570 \\
\hline $\begin{array}{l}\text { Canciones del Coronavirus } \\
\text { https://youtu.be/MY0Gy8-ezQM }\end{array}$ & elrubiusOMG & 9.520 .594 & 1.004 .807 & 17.085 & 60.975 \\
\hline $\begin{array}{l}\text { Coronavirus de Wuhan: repulsivas imágenes del } \\
\text { mercado donde se originó el brote y la alerta } \\
\text { mundial } \\
\text { https://youtu.be/yyEbH4OYYlg }\end{array}$ & CNN en Español & 9.054 .311 & 98.721 & 6.100 & 19.653 \\
\hline $\begin{array}{l}\text { Coronavirus: } 6 \text { buenas noticias sobre el nuevo } \\
\text { virus Covid- } 19 \\
\text { https://youtu.be/TBuHqj-S9F4 }\end{array}$ & BBC News Mundo & 8.901 .748 & 169.399 & 9.487 & 8.961 \\
\hline $\begin{array}{l}\text { Tienen que escuchar a este experto de COVID-19 } \\
\text { de Corea del Sur } \\
\text { https://youtu.be/xafPqcy3/wk }\end{array}$ & Asian Boss Español & 6.679 .577 & 107.884 & 4.085 & 6.901 \\
\hline $\begin{array}{l}\text { El coronavirus en China } \\
\text { https://youtu.be/Re7XOFerw3U }\end{array}$ & DW Documental & 6.674 .867 & 55.036 & 3.821 & 4.840 \\
\hline $\begin{array}{l}\text { Canción - Yo Me Quedo En Casa - Parodia } \\
\text { https://youtu.be/ZyOy6bGZxgk }\end{array}$ & Alexity & 6.200 .978 & 62.383 & 8.859 & No disponible \\
\hline $\begin{array}{l}\text { Vanesa Martín - Un canto a la vida (Video } \\
\text { Oficial) } \\
\text { https://youtu.be/q6c7ev6GfsA }\end{array}$ & Vanesa Martín & 5.672 .033 & 146.512 & 2.049 & 3.174 \\
\hline $\begin{array}{l}\text { Coronavirus (Ia canción) } \\
\text { https://youtu.be/-FqundCKB_M }\end{array}$ & Zorman & 5.575 .931 & 1.952 .69 & 14.395 & 21.390 \\
\hline
\end{tabular}


Los 39.531 vídeos han sido publicados a través de 16.720 canales. En la tabla 4 se muestra el ranking de canales en función de la cantidad de vídeos publicados sobre Covid-19 durante el período analizado (aquellos con al menos 100 vídeos). Es de destacar que todos estos canales corresponden a medios de comunicación principalmente, aunque no exclusivamente, nacionales. Europa Press es el medio de comunicación con un mayor número de vídeos recopilados, mientras que El país es el medio español con mayor promedio de visualizaciones, sólo superado por Noticias Caracol (Colombia) y Noticias Telemundo (Estados Unidos).

Entre los canales con una gran cantidad de vídeos con impacto sobre Covid-19 destaca la presencia de medios de comunicación extranjeros: Noticias Caracol (Colombia), Noticias Telemundo (Estados Unidos), TeleSUR (Venezuela) o RT en Español (Rusia). La presencia de estos canales se debe a la publicación de vídeos en los que los términos geográficos aparecían en el título o descripción de los vídeos. Del mismo modo, se observan medios de comunicación de carácter regional (NavarraTV, FaroTV Ceuta, FaroTV Melilla, Málaga 24h TV Noticias, Radio Televisión de Castilla y León, Europa Press Euskadi o CMM Castilla-La Mancha Media).

En la tabla 4 se muestran asimismo datos descriptivos de cada canal (número de subscriptores, vídeos totales publicados y visionados totales recibidos). Salvo alguna excepción (Europa Press Euskadi o Enduro DonAdrilO), todos los canales son de gran volumen, es decir, son medios muy activos en la producción de vídeos en YouTube y con gran audiencia (con independencia de la pandemia), especialmente RT en Español, Noticias Telemundo, Milenio y Noticias Caracol. Estos canales (los de mayor audiencia total en YouTube de los incluidos en la tabla 4), no sólo han publicado una cantidad considerable de vídeos sobre Covid-19 mencionando a España, sino que han logrado un impacto reseñable.

Tabla 4. Canales en YouTube con mayor número de vídeos publicados sobre Covid-19 (enero-abril de 2020)

\begin{tabular}{|c|c|c|c|c|c|c|c|}
\hline Canal & $\begin{array}{l}\text { Vídeos } \\
\text { sobre } \\
\text { Covid-19 }\end{array}$ & $\begin{array}{l}\text { Promedio de } \\
\text { views }\end{array}$ & $\begin{array}{l}\text { Promedio de } \\
\text { likes }\end{array}$ & $\begin{array}{l}\text { Promedio de } \\
\text { comments }\end{array}$ & Suscriptores & $\begin{array}{l}\text { Vídeos } \\
\text { totales }\end{array}$ & $\begin{array}{l}\text { Views } \\
\text { totales }\end{array}$ \\
\hline Europa Press & 696 & 2.301 & 23 & 6 & 343 & 96.691 & 408.136 .951 \\
\hline IB3 Notícies & 494 & 64 & 1 & 0 & 5.05 & 56.581 & 6.456 .776 \\
\hline Milenio & 300 & 85.308 & 608 & 212 & 2.110 .000 & 62.626 & 1.075 .715 .445 \\
\hline Elmundo & 253 & 78.866 & 708 & 209 & 212 & 4.279 & 139.371 .673 \\
\hline Enduro DonAdri10 & 252 & 1.647 & 28 & 2 & 2.32 & 392 & 493.281 \\
\hline Elpaís & 238 & 109.661 & 729 & 222 & 1.020 .000 & 19.577 & 625.257 .162 \\
\hline Euronews (en español) & 235 & 62.521 & 708 & 140 & 755 & 86.169 & 395.818 .366 \\
\hline Lavanguardia & 234 & 71.598 & 382 & 186 & 539 & 13.985 & 351.462 .274 \\
\hline Agencia EFE & 215 & 19.444 & 125 & 49 & 463 & 91.684 & 438.726 .974 \\
\hline NavarraTV & 208 & 625 & 6 & 1 & 17.6 & 24.841 & 13.775 .525 \\
\hline FaroTV Ceuta & 187 & 9.038 & 100 & 19 & 106 & 10.094 & 45.025 .036 \\
\hline Noticias Caracol & 180 & 217.707 & 1.407 & 360 & 2.900 .000 & 64.9 & 957.798 .172 \\
\hline Málaga 24h TV Noticias & 172 & 3.091 & 27 & 5 & 44.2 & 15.574 & 4.455 .527 \\
\hline $\begin{array}{l}\text { Radio Televisión de } \\
\text { Castilla y León }\end{array}$ & 161 & 2.815 & 16 & 5 & 129 & 29.151 & 125.216 .408 \\
\hline FaroTV Melilla & 148 & 3.494 & 48 & 4 & 19.6 & 5.754 & 8.059 .755 \\
\hline Ruptly & 132 & 15.974 & 134 & 38 & 1.200 .000 & 101.757 & 950.208 .991 \\
\hline RTVE Noticias & 124 & 11.903 & 59 & 31 & 33.8 & 723 & 4.152 .818 \\
\hline TeleSURTV & 121 & 16.743 & 243 & 58 & 1.030 .000 & 353.899 & 501.006 .709 \\
\hline Noticias Telemundo & 117 & 467.273 & 3.279 & 497 & 2.950 .000 & 33.707 & 1.083.749.998 \\
\hline RT en español & 111 & 71.325 & 846 & 214 & 3.600 .000 & 63.953 & 2.111 .978 .146 \\
\hline $\begin{array}{l}\text { CMM Castilla-La Man- } \\
\text { cha Media }\end{array}$ & 106 & 3.259 & 20 & 3 & 316 & 45.792 & 176.250 .369 \\
\hline Europa Press Euskadi & 103 & 37 & 0 & 0 & 185 & 1.222 & 131.985 \\
\hline Marca & 100 & 11.232 & 119 & 24 & 223 & 4.983 & 82.782 .292 \\
\hline
\end{tabular}

El 43\% de todos los vídeos analizados pertenece a la categoría Noticias y Política, con un alto impacto promedio en visualizaciones respecto al resto de categorías temáticas. En segundo y tercer lugar aparecen vídeos de las categorías Gente y Blogs $(23,1 \%)$ y Entretenimiento $(9,6 \%)$ respectivamente, con un elevado volumen de vídeos pero menor impacto. En cuarto y quinto lugar aparecen vídeos pertenecientes a las categorías de Educación $(5,1 \%)$ y Ciencia y Tecnología (3,5\%), menos frecuentes pero con mucho más impacto que los vídeos de entretenimiento (tabla 5). Los vídeos de Música y Comedia son los que logran en general un mayor número de visionados e impacto. 
Tabla 5. Número de vídeos sobre Covid-19 en YouTube por categoría temática

\begin{tabular}{|c|c|c|c|c|c|}
\hline Categoría & $\mathbf{N}$ & $\%$ & Promedio de views & $\begin{array}{c}\text { Promedio } \\
\text { de likes }\end{array}$ & $\begin{array}{c}\text { Promedio } \\
\text { de comments }\end{array}$ \\
\hline News \& Politics & 17.007 & 43,0 & 105.163 & 873 & 187 \\
\hline People \& Blogs & 9.162 & 23,2 & 14.502 & 351 & 35 \\
\hline Entertainment & 3.803 & 9,6 & 38.954 & 1.036 & 100 \\
\hline Education & 2.003 & 5,1 & 9.738 & 2.413 & 270 \\
\hline Science \& Technology & 1.385 & 3,5 & 10.557 & 1.477 & 152 \\
\hline Sports & 1.268 & 3,2 & 21.557 & 472 & 49 \\
\hline Music & 1.156 & 2,9 & 197.043 & 3.847 & 184 \\
\hline Travel \& Events & 889 & 2,2 & 10.551 & 153 & 24 \\
\hline NonProfits \& activism & 829 & 2,1 & 26.603 & 563 & 73 \\
\hline Film \& Animation & 557 & 1,4 & 2.332 & 555 & 84 \\
\hline Howto \& Style & 510 & 1,3 & 3.594 & 586 & 55 \\
\hline Gaming & 373 & 0,9 & 12.099 & 361 & 33 \\
\hline Comedy & 293 & 0,7 & 184.146 & 7.697 & 523 \\
\hline Autors \& Vehicles & 229 & 0,6 & 67.425 & 976 & 119 \\
\hline Pets \& Animals & 67 & 0,2 & 7.462 & 269 & 98 \\
\hline
\end{tabular}

Dentro de la categoría Educación se encuentran los canales oficiales de las universidades. En el caso concreto de España, se identifican dentro de esta categoría vídeos de hasta 35 universidades españolas, que aportan 137 vídeos. El vídeo de una universidad española con mayor número de visualizaciones es a 'VIU. Nos unen tus metas. Anuncio TV 2020-20', de la Universidad Internacional de Valencia (VIU), con 2.880 .342 views (pero solamente 10 likes), mientras que el vídeo con mayor número de likes corresponde al 'Mensaje del rector a los estudiantes de la Universidad de Navarra', con apenas 207 likes. La universidad con mayor cantidad de vídeos recopilados, con independencia de su impacto, corresponde a la Universitat Autònoma de Barcelona (19 vídeos).

Por otro lado, la categoría Ciencia y Tecnología incluye una gran cantidad de hospitales y centros de salud, tanto nacionales como regionales y locales. El vídeo con mayor número de visualizaciones de un centro/organización español
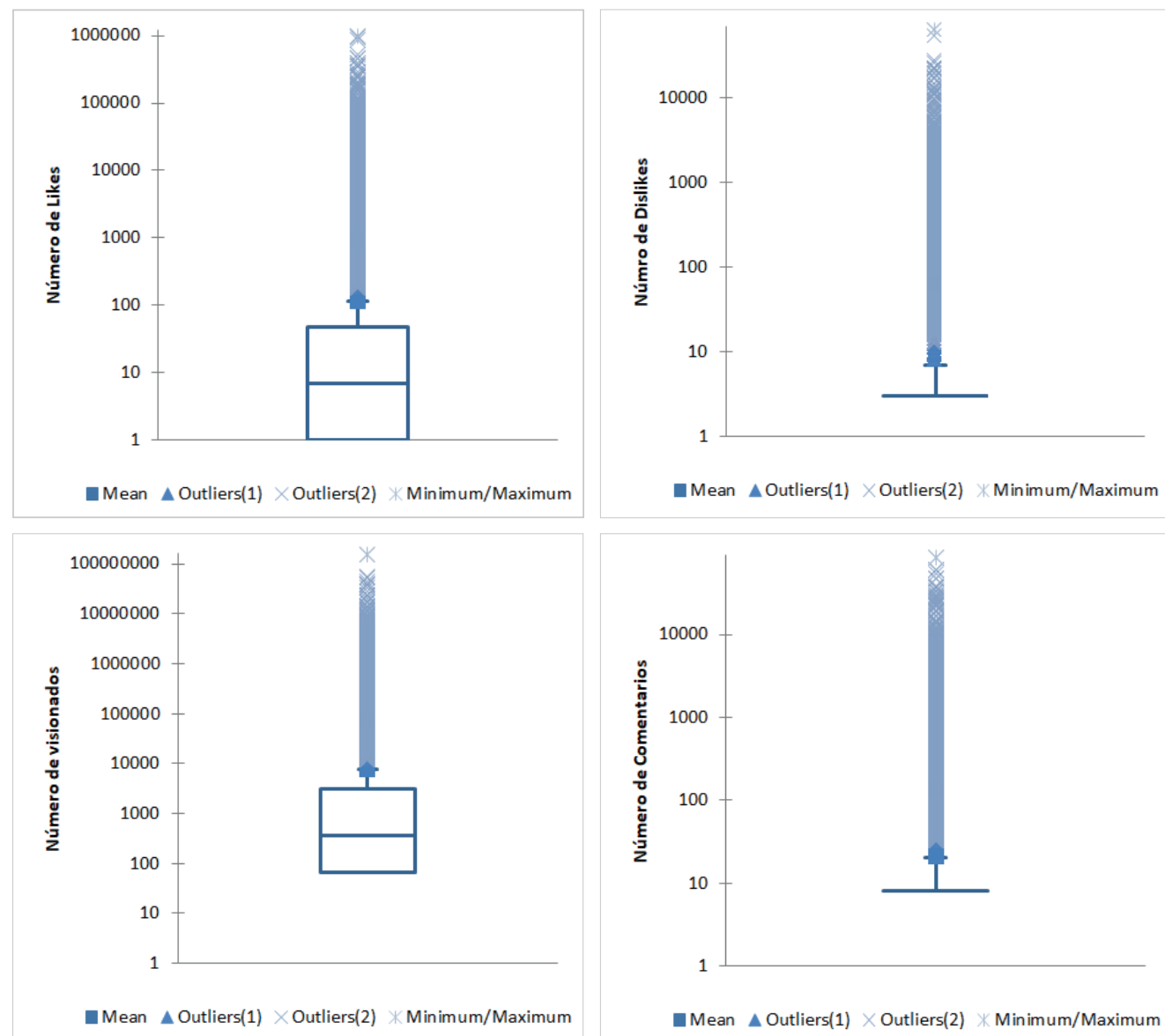

Mean $\Delta$ Outliers(1) $\times$ Outliers(2) $\times$ Minimum/Maximum

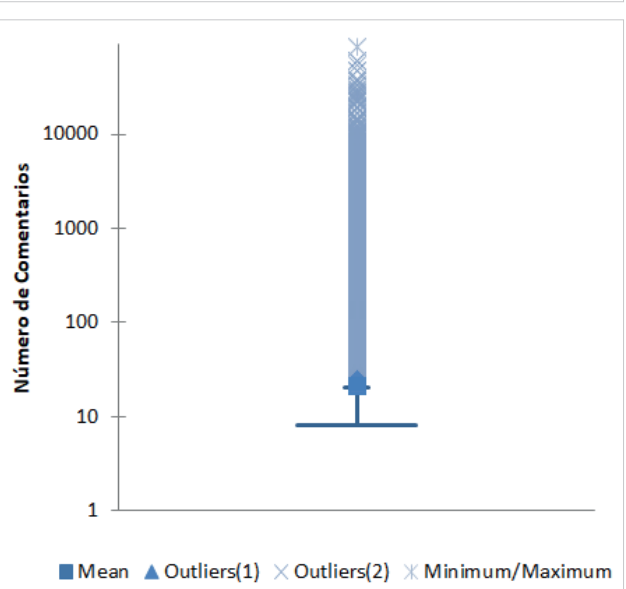

Figura 5. Diagramas de caja (box plots). Métricas a nivel de vídeo: likes, dislikes, views y comentarios. Nota: el eje Y se muestra en escala logarítmica. 

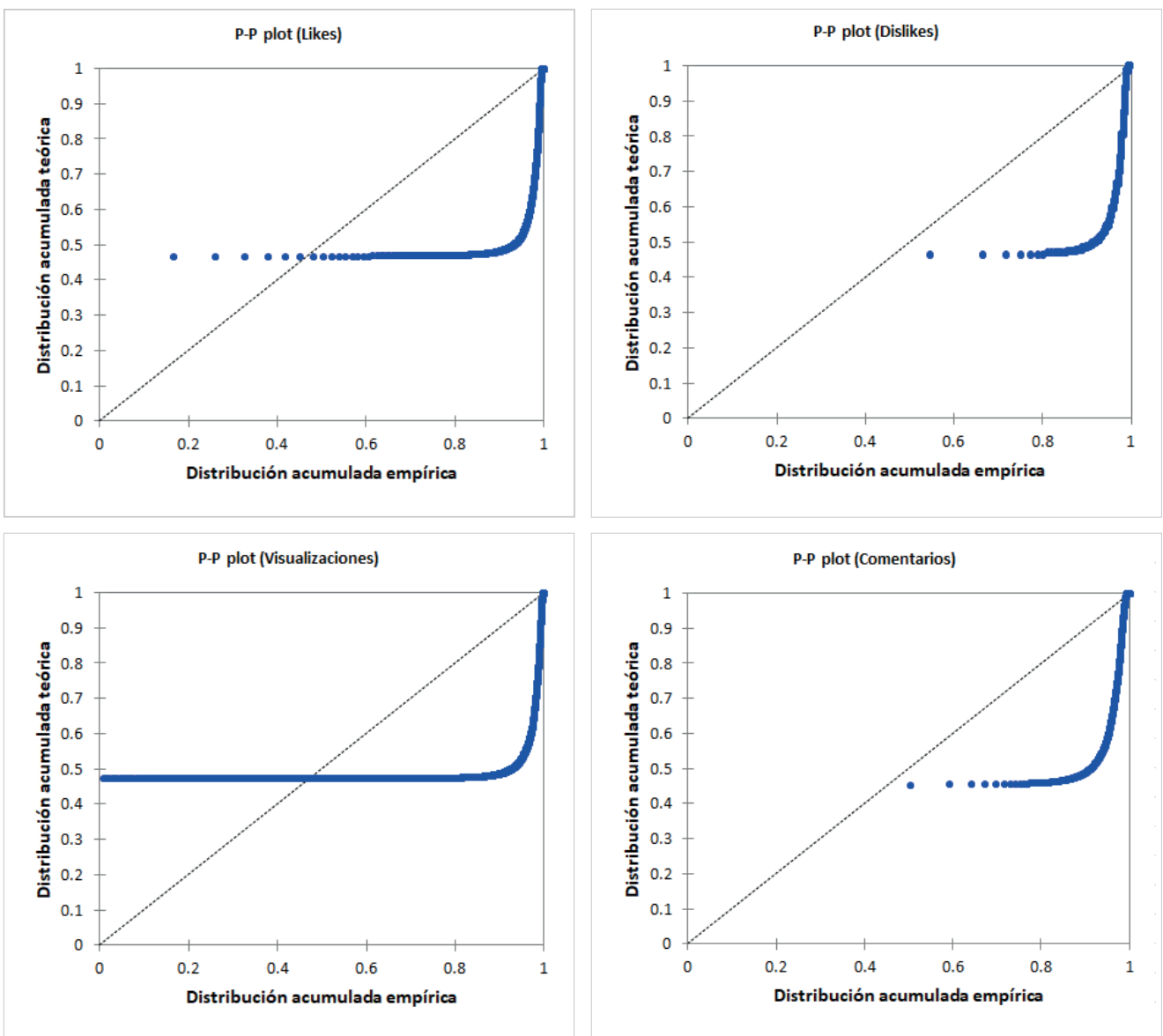

Figura 6. Distribución para las métricas a nivel de vídeo: likes, dislikes, views y comentarios

relacionado con la salud corresponde a 'Cómo afecta el \#coronavirus a los niños', publicado por la Asociación Española de Pediatría (428.251 views). El vídeo con más likes fue 'Paciente con coronavirus recibe el alta de UCI en IMED', del Hospital IMED Levante (3.051 likes). El canal español dentro de esta categoría temática con mayor cantidad de vídeos fue el Hospital Clínico de Barcelona (58 vídeos recopilados).

En lo que se refiere a las métricas de impacto de los vídeos, se aprecian distribuciones altamente sesgadas en la cantidad de likes, dislikes, views y comentarios (figuras 5 y 6 ).

Tomando 1.000 visualizaciones como valor de referencia (cantidad a partir de la cual YouTube paga a los propietarios de los vídeos a través de una tasa denominada CPM, cost per mille o cost per thousand) se considera que el número de visualizaciones obtenidas es alto (media de 70.908; mediana de 359). El 36,6\% de los vídeos (14.485) logran al menos 1.000 visualizaciones.

Los resultados en número de likes (media de 954; mediana de 7), comentarios recibidos (media de 133; mediana de 0) y dislikes (media de 64; mediana de 0) son menores. Con todo, el valor de este último parámetro es significativo (hay 471 vídeos con más de 1.000 dislikes), aunque fuertemente sesgado (21.110 vídeos reciben 0 dislikes).

En la figura 7 se incluye el impacto de los vídeos en función de su fecha de publicación. Se puede observar un impacto fuerte especialmente en el número de visualizaciones (4.020 vídeos logran un promedio de al menos 1.000 visualizaciones por día).

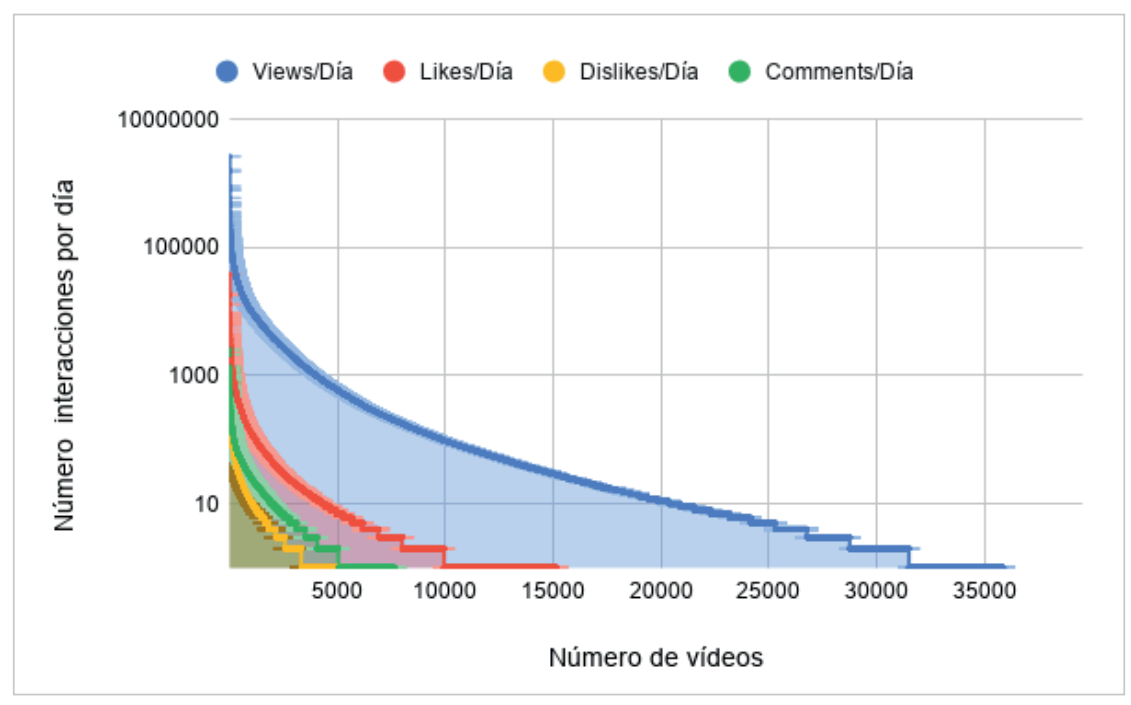

Figura 7. Número de views, likes, dislikes y comentarios por día de visualización. Nota: el eje Y (número de interacciones por día) se muestra en escala logarítmica. 
La correlación entre las métricas es igualmente muy elevada, confirmando que los vídeos con mayor número de visualizaciones son los que por lo general obtienen un mayor número de likes y de comentarios. Del mismo modo, el número de dislikes también correlaciona con los vídeos de mayor impacto. En la tabla 6 se ofrecen los coeficientes de determinación ( $R^{2}$ Spearman obtenidos; $\alpha<0,01$ ).

Tabla 6. Coeficientes de determinación $\left(\mathrm{R}^{2}\right)$ entre las métricas de impacto de vídeos

\begin{tabular}{|l|c|c|c|}
\hline \multicolumn{1}{|c|}{ Métricas } & Visualizaciones & Likes & Dislikes \\
\hline Visualizaciones & $\mathbf{1}$ & 0,80 & 0,64 \\
\hline Likes & 0,80 & $\mathbf{1}$ & 0,58 \\
\hline Dislikes & 0,64 & 0,58 & $\mathbf{1}$ \\
\hline Comentarios & 0,57 & 0,64 & 0,54 \\
\hline
\end{tabular}

En lo que respecta a la duración de los vídeos, se observa igualmente una distribución muy sesgada, con una alta concentración de vídeos cuya duración oscila entre 100 y 1.000 segundos (figura 8), principalmente de medios de comunicación (la API de YouTube devuelve una duración igual a 0 para algunas retransmisiones en streaming).

La duración de los vídeos no presenta ningún tipo de correlación con las métricas de impacto. Con todo, los datos indican que los vídeos precisamente de una duración entre 100 segundos y 10.000 segundos ( 2 horas y 48 minutos aproximadamente) son los que por lo general obtienen un mayor número de visionados (figura 9). Por tanto, el impacto queda influido por otras variables (interés, calidad de los vídeos o canal), mientras que la duración tiene una incidencia menor.

\section{Discusión}

Los resultados obtenidos deben entenderse en el contexto de la realización de búsquedas relacionadas con la enfermedad (Covid-19) y delimitadas por términos de consulta geográficos (España). Por tanto, entre los registros analizados se incluyen vídeos que no han sido publicados en España ni en español, pero que pueden mencionar al territorio nacional

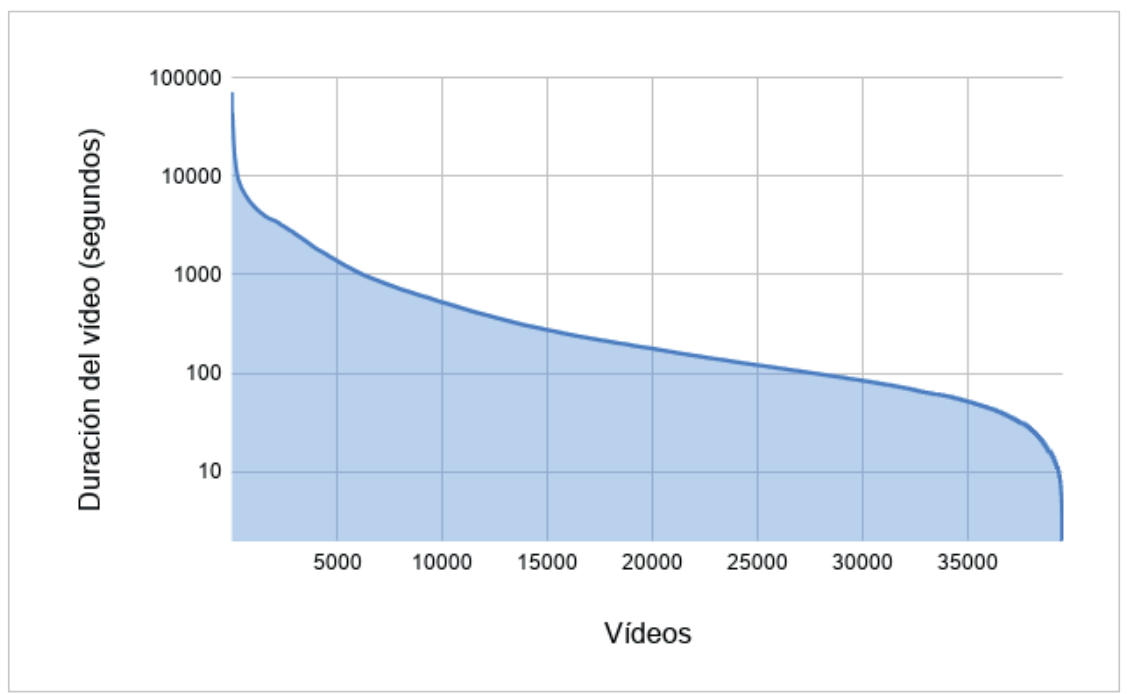

Figura 8. Distribución de la duración de los vídeos sobre Covid-19 en YouTube. Nota: el eje Y (duración del vídeo en segundos) se muestra en escala logarítmica.

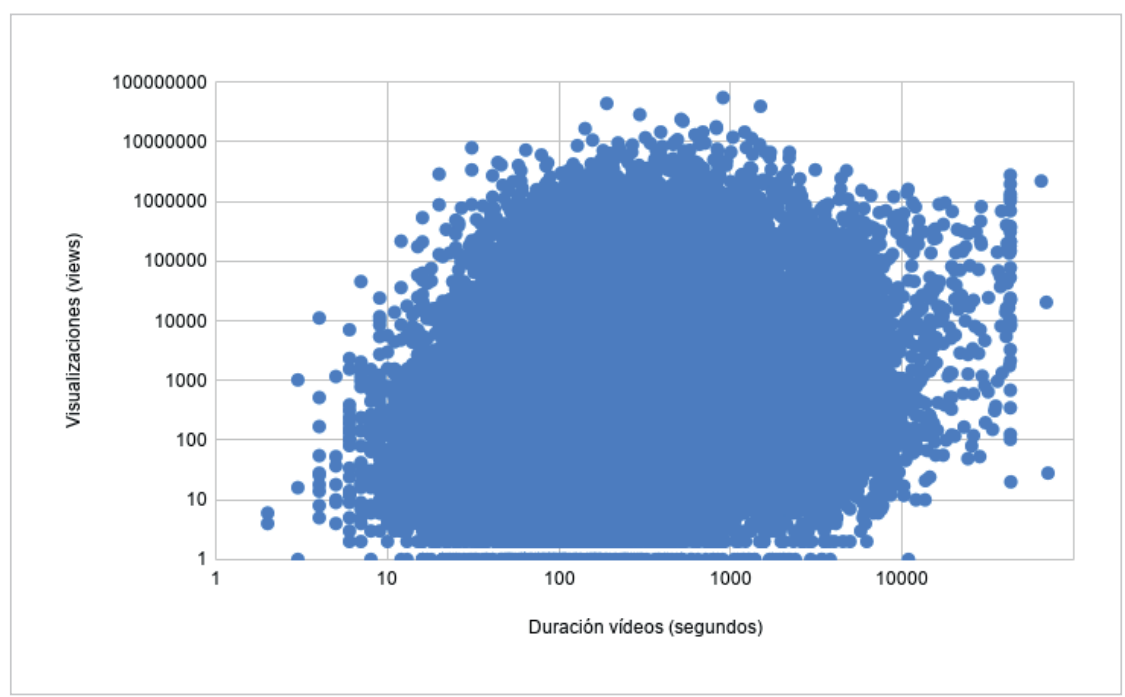

Figura 9. Gráfico de dispersión (scatter plot) entre la duración de los vídeos y el número de visualizaciones en vídeos sobre Covid-19 en YouTube.

Nota: los ejes se muestran en escala logarítmica.

(noticias extranjeras que cubran el

desarrollo de la pandemia en España o bien hilos de discusión en los vídeos). Es posible igualmente que ciertos canales dispongan de vídeos relacionados con la pandemia que hayan logrado mejores métricas de impacto. Sin embargo, YouTube no los ha considerado relevantes y no han sido recuperados por el algoritmo de relevancia de la plataforma en ninguna de las 1.602 consultas realizadas.

A pesar de la inclusión de descriptores geográficos en las consultas, YouTube devolvió una gran cantidad de vídeos no relacionados con España, ni directa ni indirectamente. La razón se atribuye a la aparición de alguno de los términos geo- 
gráficos usados entre los comentarios o contenidos de la descripción del vídeo. Este hecho limita la utilización de YouTube en este tipo de estudios.

Debe considerarse asimismo la alta variabilidad de estos datos. Por un lado, las métricas están en constante evolución (aumentando el número de visualizaciones, likes o comentarios). Por otro lado, son depositados y difundidos nuevos vídeos a través de YouTube, cuyas métricas irán creciendo. Por ese motivo, los resultados deben ser considerados como una fotografía fija hecha en un momento determinado del período de confinamiento (vídeos publicados de enero a abril de 2020, con métricas medidas a fecha de 6 de mayo).

En lo que respecta a YouTube como fuente de información, los resultados han mostrado ciertas limitaciones e inconsistencias importantes a destacar:

En primer lugar, se desconoce el tamaño real de YouTube en general, y la cantidad de vídeos sobre Covid-19 en particular. Por tanto, los datos obtenidos constituyen una muestra, representativa en el sentido de cubrir todos aquellos vídeos con un mínimo de impacto.

En segundo lugar, los criterios de ordenación de resultados utilizados (fecha de publicación, rating, relevancia, título, número de vídeos, número de visionados) han mostrado un elevado solapamiento. De un total de 200.647 vídeos recuperados, el 63,5\% eran duplicados. A pesar del alto solapamiento, se estima necesario el uso de todos los criterios de ordenación pues han permitido obtener una mayor cantidad de vídeos y ampliar de este modo el dataset analizado.

En tercer lugar, ha sido necesaria la implementación de varias etapas de limpieza de datos, pues la API de YouTube devolvía vídeos que no tenían relación alguna con Covid-19. El 54,2\% de los vídeos recopilados (usando consultas específicas) no guardaban relación con la pandemia.

En cuarto lugar, la presencia de ciertos medios de comunicación podría deberse a un intenso trabajo de SEO, tanto a nivel de canal como de vídeo. Trabajos anteriores han mostrado cómo algunos de los principales cibermedios españoles aplican técnicas específicas de SEO (search engine optimization) para posicionar vídeos en YouTube (Lopezosa; Orduña-Malea; Pérez-Montoro, 2020). Este hecho podría proporcionar una ventaja extra a estos canales a la hora de obtener un mayor número de visualizaciones, unido al hecho de que los usuarios deseen elegir medios de comunicación con el fin de consumir noticias de mayor calidad en un tema de salud pública.

En quinto lugar, revisiones manuales de los datos revelaron técnicas de SEO para mejorar la posición de los vídeos en YouTube mediante la incrustación de términos relacionados con la pandemia en los campos de descripción o comentarios, con el fin de aprovechar el incremento del número de consultas en YouTube relacionadas con el coronavirus para obtener más visitas, aunque los vídeos no guardaran ninguna relación con la pandemia (venta de coches, panorámicas de Miami, métodos de adelgazamiento, etc.).

Finalmente, los vídeos recopilados mostraron en promedio unas métricas de impacto significativas, especialmente en número de visualizaciones. Estos resultados no pueden compararse con resultados previos similares que puedan servir de referencia. Khatri et al. (en prensa) analizan 47 vídeos en inglés y 20 en chino. A pesar de no ser comparables los resultados, estos autores obtienen para los vídeos en inglés un valor promedio de 288.545 visualizaciones y 3.889 likes. Estos números son inferiores en el caso de los vídeos en chino (91.950 visualizaciones y 640 likes). En el caso de este trabajo, se ha obtenido un valor promedio de 70.908 visualizaciones y de 954 likes, sobre la base de 39.531 vídeos. Basch et al (2020) analizan los 100 vídeos con mayor número de visualizaciones publicados en el mundo durante enero de 2020, obteniendo un valor promedio de 1.252.869 visualizaciones. Estos autores ya constatan una amplia presencia de medios de comunicación entre esos vídeos de alta visualización, así como una presencia reseñable (14\%) de vídeos en español. En el caso de este trabajo, el promedio de visualizaciones obtenido para los 100 vídeos con mayor cantidad de views asciende a 12.178.543. Finalmente, el trabajo de Cinelli et al. (2020) no proporciona valores promedio de visualizaciones o likes.

\section{Conclusiones}

Los resultados obtenidos muestran un incremento del número de vídeos publicados en YouTube relacionados con Covid-19 en España a partir de marzo de 2020. La evolución del número de publicaciones por día guarda asimismo relación con acontecimientos sociales y políticos relacionados con la evolución de la pandemia y las regulaciones del confinamiento (el estado de alarma decretado y sus sucesivas prórrogas).

Los canales con mayor número de publicaciones sobre Covid-19 identificados corresponden principalmente a medios de comunicación, tanto nacionales (Europa Press, El mundo, El país, La vanguardia, Agencia EFE) como regionales (IB3 Notícies, Navarra Televisión, Faro TV Ceuta, Málaga 24h TV Noticias o Radio Televisión de Castilla y León). Del mismo modo, se identifica una alta presencia de medios extranjeros (Noticias Caracol, TeleSUR o RT en español).

Entre los vídeos más populares (en términos de visualizaciones) destacan documentales sobre el origen del co-
YouTube no es actualmente una fuente precisa a la hora de realizar análisis informétricos 
ronavirus (no necesariamente contrastados por la comunidad científica) y eventos musicales realizados con motivo de la pandemia. Los vídeos en las categorías de Educación y Ciencia y Tecnología son más escasos en cantidad, pero obtienen un impacto significativo, aunque superados en visualizaciones por los vídeos de Noticias y Política, Música y Comedia.

Finalmente, se concluye que YouTube no es actualmente una fuente precisa para ser utilizada en análisis informétricos al requerir de un esfuerzo considerable de filtrado y limpieza de los datos obtenidos. A pesar de ello, y teniendo en cuenta la magnitud de la muestra analizada (39.702 vídeos filtrados), se considera que los resultados obtenidos reflejan adecuadamente la cobertura en YouTube de vídeos sobre Covid-19 relacionados con la pandemia en España que han generado un mínimo de impacto.

\section{Nota}

El dataset de vídeos (tanto el listado completo inicial como el filtrado final) se encuentra disponible en abierto en la siguiente dirección:

https://riunet.upv.es/handle/10251/143671

\section{Referencias}

Basch, Corey H.; Basch, Charles E.; Ruggles, Kelly V.; Hammond, Rodney (2015). “Coverage of the Ebola virus disease epidemic on YouTube". Disaster medicine and public health preparedness, v. 9, n. 5, pp. 531-535.

https://doi.org/10.1017/dmp.2015.77

Basch, Corey H.; Fung, Isaak-Chun-Hai; Hammond, Rodney N.; Blankenship, Elizabeth B.; Tse, Zion-Tsz-Ho; Fu, KingWa; Ip, Patrick; Basch, Charles E. (2017). "Zika virus on YouTube: an analysis of English-language video content by source". Journal of preventive medicine and public health, v. 50, n. 2, pp. 133-140.

https://doi.org/10.3961/jpmph.16.107

Basch, Corey H.; Hillyer, Grace C.; Meleo-Erwin, Zoe C.; Jaime, Christie; Mohlman, Jan; Basch, Charles E. (2020). "Preventive behaviors conveyed on YouTube to mitigate transmission of Covid-19: Cross-sectional study". JMIR public health and surveillance, v. 6, n. 2, e18807.

https://doi.org/10.2196/18807

Berec (2020). Berec summary report on the status of internet capacity in light of Covid-19 crisis.

https://berec.europa.eu/eng/document_register/subject_matter/berec/download/0/9250-berec-summary-report-onthe-status-of-in_0.pdf

Burton, Scott; Morris, Richard; Dimond, Michael; Hansen, Joshua; Giraud-Carrier, Christophe; West, Joshua; Hanson, Carl; Barnes, Michael (2012). "Public health community mining in YouTube". In: Proceedings of the $2^{\text {nd }}$ ACM SIGHIT International health informatics symposium, pp. 81-90.

https://doi.org/10.1145/2110363.2110376

Cinelli, Matteo; Quattrociocchi, Walter; Galeazzi, Alessandro; Valensise, Carlo-Michele; Brugnoli, Emanuele; Schmidt, Ana-Lucia; Zola, Paola; Zollo, Fabiana; Scala, Antonio (2020). "The Covid-19 social media infodemic". arXiv preprint arXiv:2003.05004.

https://arxiv.org/abs/2003.05004

Drozd, Brandy; Couvillon; Emily; Suárez, Andrea (2018). "Medical YouTube videos and methods of evaluation: literature review". JMIR medical education, v. 4, n. 1, e3.

https://doi.org/10.2196/mededu.8527

España (2020). "Real decreto 463/2020, de 14 de marzo, por el que se declara el estado de alarma para la gestión de la situación de crisis sanitaria ocasionada por el Covid-19”. Boletín oficial del Estado, n. 67, pp. 25390-25400. https://www.boe.es/eli/es/rd/2020/03/14/463

Gevers, Alex (2020). "Coronavirus pandemic and online media consumption: settling into the new normal". Comscore. https://www.comscore.com/Insights/Blog/Coronavirus-pandemic-and-online-media-consumption-settling-into-theNew-Normal

Hayanga, Awori J.; Kaiser, Heather E. (2008). "Medical information on YouTube". JAMA, v. 299, n. 12, pp. 1424-1426. https://doi.org/10.1001/jama.299.12.1424-b

Hidalgo-Pérez, Montse (2020). “Dime quién eres y te diré cómo matas el tiempo en la red”. El país, 17 abril. https://elpais.com/tecnologia/2020-04-17/dime-quien-eres-y-te-dire-como-matas-el-tiempo-en-la-red.html

Huang, Chaolin; Wang, Yeming; Li, Xingwang; Ren, Lili; Zhao, Jianping; Hu, Yi; Zhang, Li; Fan, Guohui; Xu, Jiuyang et al. (2020). "Clinical features of patients infected with 2019 novel coronavirus in Wuhan, China". The lancet, v. 395, n. 10223, pp. 15-21.

https://doi.org/10.1016/S0140-6736(20)30183-5 
Johns Hopkins University (2020). Coronavirus Resource Center.

https://coronavirus.jhu.edu

Khatri, Priyanka; Singh, Shweta R.; Belani, Neeta-Kesu; Yeong, Yin-Leng; Lohan, Rahul; Lim, Yee-Wei; Teo, Winnie Z. Y. (in press). "YouTube as source of information on 2019 novel coronavirus outbreak: a cross sectional study of English and Mandarin content". Travel medicine and infectious disease.

https://doi.org/10.1016/j.tmaid.2020.101636

Lopezosa, Carlos; Orduña-Malea, Enrique; Pérez-Montoro, Mario (2019). “Making video news visible: Identifying the optimization strategies of the cybermedia on YouTube using web metrics". Journalism practice, v. 4, n. 4, pp. 465-482. https://doi.org/10.1080/17512786.2019.1628657

Madathil, Kapil-Chalil; Rivera-Rodríguez, A. Joy; Greenstein, Joel S.; Gramopadhye, Anand K. (2015). "Healthcare information on YouTube: a systematic review". Health informatics journal, v. 21, n. 3, pp. 173-194.

https://doi.org/10.1177/1460458213512220

Nokia (2020). Network traffic insights in the time of coronavirus disease (Covid-19): Nokia Deepfield network intelligence report. https://onestore.nokia.com/asset/207327

Oller-Arlandis, Vicent; Oller-Arlandis, Vanessa-Esperanza (2017). "YouTube como fuente de información sanitaria y divulgación del conocimiento sobre cuidados paliativos en el domicilio”. Hospital a domicilio, v. 1, n. 3, pp. $153-166$. https://doi.org/10.22585/hospdomic.v1i3.23

Orduña-Malea, Enrique (2019). “Google Trends: analítica de búsquedas al servicio del investigador, del profesional y del curioso". Anuario ThinkEPI, v. 13, e13inf01. https://doi.org/10.3145/thinkepi.2019.e13inf01

Pandey, Ambarish; Patni, Nivedita; Singh, Mansher; Sood, Akshay; Singh, Gayatri (2010). "YouTube as a source of information on the H1N1 influenza pandemic". American journal of preventive medicine, v. 38, n. 3, e1-e3.

https://doi.org/10.1016/j.amepre.2009.11.007

Pathak, Ranjan; Poudel, Dilli-Ram; Karmacharya, Paras; Pathak, Amrit; Aryal, Madan-Raj; Mahmood, Maryam; Donato, Anthony A. (2015). "YouTube as a source of information on Ebola virus disease". North American journal of medical sciences, v. 7, n. 7, pp. 306-309.

https://doi.org/10.4103/1947-2714.161244

Sampson, Margaret; Cumber, Jordi; Li, Claudia; Pound, Catherine M.; Fuller, Ann; Harrison, Denise (2013). "A systematic review of methods for studying consumer health YouTube videos, with implications for systematic reviews". PeerJ, v. 1, e147. https://doi.org/10.7717/peerj.147

Statista (2020). YouTube.

https://www.statista.com/study/15475/YouTube-statista-dossier

Syed-Abdul, Shabbir; Fernández-Luque, Luis; Jian, Wen-Shan; Li, Yu-Chuan; Crain, Steven; Hsu, Min-Huei; Wang, JaoChin; Khandregzen, Dorjsure; Chuluunbaatar, Enkhzaya; Anh Nguyen; Phung; Liou, Der-Ming (2013). "Misleading health-related information promoted through video-based social media: Anorexia on YouTube". Journal of medical internet research, v. 15, n. 2, e30.

https://doi.org/10.2196/jmir.2237

Telefónica (2020). "Telefónica registra durante la crisis del Covid-19 un crecimiento en su tráfico de internet equivalente al de todo el año pasado". Telefónica, 15 abril.

https://bit.ly/2WKNXLI

Thelwall, Mike (2012). Introduction to Webometric Analyst 2.0: A research tool for social scientists. http://lexiurl.w/v.ac.uk/searcher/IntroductionToWebometricAnalyst2.doc

Walton, Laura R.; Seitz, Holli H.; Ragsdale, Kathleen (2012). "Strategic use of YouTube during a national public health crisis: the CDC's response to the 2009 H1N1 flu epidemic". Case studies in strategic communication, v. 1, n. 3, pp. $25-37$. https://doi.org/10.1123/ijsc.4.1.99

WHO (2003). Severe acute respiratory syndrome (SARS).

https://www.who.int/csr/sars/en/ea56r29.pdf

WHO (2020a). Statement on the second meeting of the International Health Regulations (2005) Emergency Committee regarding the outbreak of novel coronavirus (2019-nCoV).

https://bit.ly/2ZmHZSM

WHO (2020b). WHO Director-General's opening remarks at the media briefing on COVID-19 - 11 March 2020.

https://bit.ly/3bUz265 